\title{
Description of new Dryocoetes (Coleoptera, Curculionidae, Scolytinae) species from Afghanistan and Northern India and redescription of Scolytoplatypus kunala Strohm
}

\author{
Michail Yu. Mandelshtam ${ }^{1, \dagger}$, Alexander V. Petrov ${ }^{2, \ddagger}$
}

I Bolshoy prospect, building 76, apt. 53, St.Petersburg, 199026, Russia 2 Department of Ecology and Forest Protection, Moscow State Forest University, Mytishchi-5, 141005 Moscow

† urn:lsid:zoobank.org:author:0C91E955-CE2E-46ED-9579-A9B657321AB0

† urn:lsid:zoobank.org:author:6529D938-0B37-447D-89E5-602EE83B66D0

Corresponding author: Michail Yu. Mandelshtam (michail@MM13666.spb.edu)

Academic editor: R.A. Beaver| Received 31 August 2009 | Accepted 15 February 2010 | Published 17 September 2010

urn:lsid:zoobank.org:pub:41E5CD30-690A-4D68-A35F-8C286D7BE4CA

Citation: Mandelshtam MY, Petrov AV (2010) Description of new Dryocoetes (Coleoptera, Curculionidae, Scolytinae) species from Afghanistan and Northern India and redescription of Scolytoplatypus kunala Strohm. In: Cognato AI, Knížek M (Eds) Sixty years of discovering scolytine and platypodine diversity: A tribute to Stephen L. Wood. ZooKeys 56: 179-190. doi: 10.3897/zookeys.56.525

\begin{abstract}
A new bark beetle species, Dryocoetes brownei from Northern India and Afghanistan, is described as a new to science and redescription of Scolytoplatypus kunala Strohmeyer, 1908, previously known only from the female holotype, is provided.
\end{abstract}

\section{Keywords}

Curculionidae, Scolytinae, Dryocoetes, Scolytoplatypus, Afghanistan, Northern India, new species

\section{Introduction}

One more new species of Scolytinae in the genus Dryocoetes was discovered during study of materials kept in Natural History Museum, London (NHML), and several more examples of this species were found in the O.N. Kabakov collection from Afghanistan. 
Oriental Scolytoplatypus species were recently reviewed by Beaver and Gebhardt (2006). This paper gave new insights into the taxonomy of the genus and has helped researchers to describe new species from the region. However, treatment of Scolytoplatypus kunala Strohmeyer, 1908 in most papers, including the cited one, is doubtful or erroneous. Schedl (1973) considered S. kunala to be a senior synonym of $S$. darjeelingi Stebbing, 1914, but Beaver and Gebhardt (2006) treated S. kunala as a junior synonym of S. daimio Blandford, 1893 and S. siomio Blandford, 1893, but as a distinct species from $S$. darjeelingi. Importantly, all Scolytoplatypus species known from Himalaya, besides $S$. kunala, were recorded only in Eastern Himalaya, whereas $S$. kunala was discovered in Kashmir Province, Western Himalaya (Strohmeyer, 1908). We have found three males and two females of Scolytoplatypus species collected by O.N. Kabakov in Afghanistan in Russian collections. After comparison of these specimens with the female holotype of $S$. kunala we consider these specimens from Afghanistan to be conspecific with $S$. kunala and provide redescription of both male and female of this poorly known species. S. kunala is reinstated here as separate good species. So far we extend the geographical range of Oriental Scolytoplatypus to the west and consider S. kunala to be the most "western" Scolytoplatypus species from Asia.

\section{Systematics}

\section{Dryocoetes brownei, Mandelshtam \& Petrov, sp. $\mathbf{n}$.} urn:Isid:zoobank.org:act:6510C1A7-5D09-45D5-A994-2AD2CAE8522F

Description. Male. Holotype (NHML) body length $5.1 \mathrm{~mm}$, width $2.0 \mathrm{~mm}$, other specimens (four female paratypes) 4.8-5.0 $\mathrm{mm}$ in length. Body reddish brown, essentially as in Dryocoetes autographus Ratz. All five studied specimens appear to be mature, not teneral.

Frons is rather densely but not coarsely, uniformly punctured, with an enlarged puncture in center forming a small fovea. Frontal surface shining, without reticulation. Vertex more sparsely punctured and with smaller punctures. A median longitudinal black line (sulcus) on vertex probably indicates internal strengthening of the head. Frons with rather long, fairly sparse, yellowish hair-like setae, not forming tufts typical of females of Dryocoetes species. Hair-like setae significantly longer at lateral sides of pubescent frontal area. Epistoma with long dense yellowish setae directed downwards. Eyes rather large, emarginate anteriorly. Antennae typical for genus: funiculus 5-segmented and club obliquely truncate with recurved sutures on anterior face, and one suture near apex on posterior face.

Pronotum slightly longer than wide (1.9 vs. $1.8 \mathrm{~mm})$; sides subparallel in basal three fourth and apex simply rounded, without teeth on anterior margin. Pronotal surface generally granulate, more coarsely anteriorly, punctured area very small and restricted to central portion of pronotal base around impunctate median line extending approximately one fifth of pronotal length only. Pronotal surface between granules 
shining, without any reticulation. Sides and anterior margin of pronotum with long, curved, yellow hair-like setae.

Scutellum large, flat, flush with elytral surface, of same reddish color as elytra.

Elytra slightly wider $(2.0$ vs. $1.9 \mathrm{~mm})$ than pronotum, nearly cylindrical, only slightly widened towards apex, $3.2 \mathrm{~mm}$ long. Elytra extremely coarsely punctured on the disk, especially on striae 1-3 (Fig. 1) . Juxtasutural stria not impressed both on disk and on declivity, its punctures nearly as deep and as large as punctures of second stria. Interstriae in central part of disk narrow, 1.5-2.0 times narrower than striae, rather convex and shining, with minute punctures nearly 5 times smaller in diameter than strial punctures, in one irregular row on each interstria; minute tubercles present on interstriae on disk, but not on declivity.

Declivity slightly flattened, convex, not steep, dull. Ventrolateral sides of declivity not armed and lacking minute tubercles on declivital surface. First and second interstriae are widened at declivity. Strial punctures of first and second interstriae on declivity larger than punctures of other striae, but more than two times smaller than on disk. First and second striae slightly divergent towards elytral apex. Suture appearing only slightly convex on declivity because juxtasutural striae are not deepened. Elytra with rather long yellow interstrial hair-like setae, longer laterally and on the declivity; strial hair-like setae recumbent and approximately 5 times shorter that interstrial setae.

Legs typical for the genus, protibia with 5 socketed teeth on outer surface, mesoand metatibiae each with 5 spines on outer margin.

Underside of body reddish brown, abdomen covered with rather long setae on posterior margin of ventrites.

Female. Similar to male, but the frons with a dense tuft of long yellow hair-like setae.

Etymology. The new species is dedicated to the eminent British coleopterologist F.G. Browne, who first labeled the holotype as a possible new species.

Type material. Holotype (male) is deposited in NHML. Labels of the holotype are as follows: Kashmir: Gulmarg. vi - 1931. Dr. M.Cameron. B.M. 931-452.// Dryocoetes sp.n. det. F.G.B. 1967 (in black ink, in F.G. Browne's handwriting)// Possibly one of Beeson's undescr. spp. - deobanos himalahinorum [sic!] (in black ink, in F.G. Browne's handwriting). Paratypes (4 females) (including female allotype): Afghan[istan], Nurestan N.Waygal 2500 m., 10.VII.1972, Kabakov [leg.], 1 spec. in Zoological Institute, St.Petersburg (ZISP) and 3 spec. in A.V. Petrov private collection.

Diagnosis and comparison with other Indian Dryocoetes species. A new barkbeetle is described from Northern India that differs from all other Indian species of the genus Dryocoetes by the exceptionally large punctures of the elytral discal striae and by the large size of the body.

In India, four species of genus Dryocoetes were previously reported to occur, namely D. hewetti Stebbing, 1908, D. himalayensis Strohmeyer, 1908, D. quadrisulcatus Strohmeyer, 1908 and $D$. indicus Stebbing, 1914. We were able to study all these four species in the Zoological Museum of Moscow University (ZMMU). The first of them has a spatulate antennal club, and extremely long declivital pubescence, and was correctly transferred to the genus Taphrorychus (Wood and Bright, 1992). D. himalayensis and D. quadrisulcatus differ from both $D$. indicus and $D$. brownei by the much smaller body size 


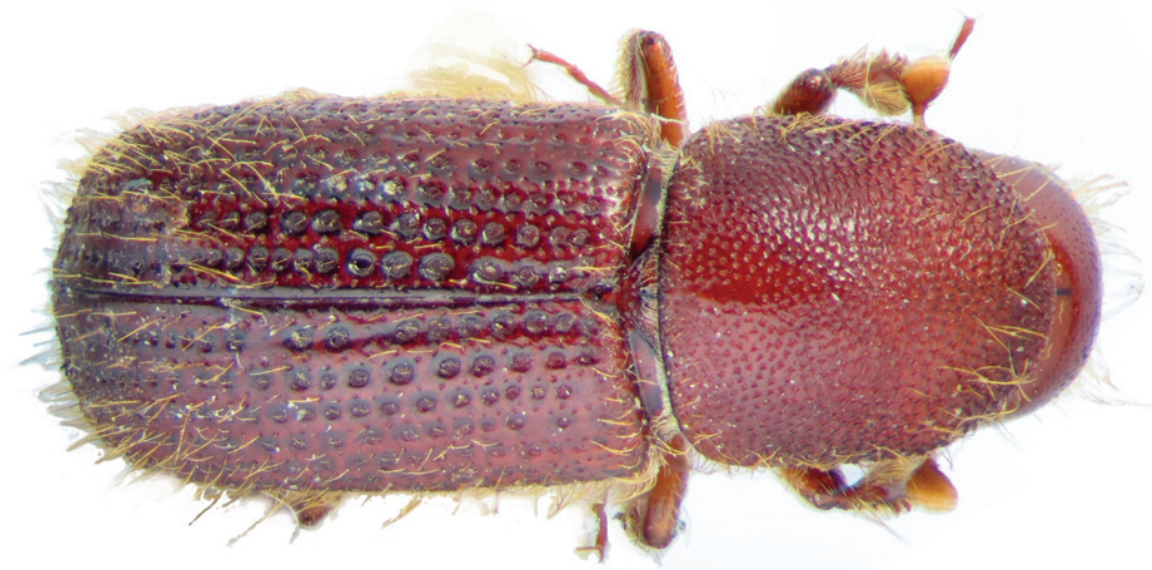

Figure I. Dryocoetes brownei, HT, male, dorsal view.

and by the strongly deepened first striae on the disk and the declivity. Although this feature is more evident in males of these species, it is also developed in the females. $D$. indicus is also smaller in size $(4.0 \mathrm{~mm}$ vs $5.1 \mathrm{~mm})$ than $D$. brownei, has equally punctured striae and interstriae on the disk, and minute but evident tubercles on the declivity.

\section{Scolytoplatypus kunala Strohmeyer, 1908}

Material examined: Holotype (female): Kashmir, Pir Panjal, Rost [leg.]// Female sign // Type // Spongocerus kunala Strohm. Determ. Strohmeyer // Coll. Strohmeyer // Holotypus (on red paper). Holotype is deposited in Senckenberg Deutsches Entomologisches Iinstitut (SDEI). Additional material examined: 2 males, Afghan[istan], Nurestan, N. Waygal, 2750 m., 9.7.1972, Kabakov [leg.] (Zoological Museum of Moscow University and A.V.Petrov private collection); 1 more male and 2 females with labels: Afghan[istan] Nurestan N. Waygal 3500 m. 2.7.1972 Kabakov [leg.] (A.V. Petrov private collection).

Description. Male. Length $2.7 \mathrm{~mm}$, body stout, 2.1 times as long as wide (Figs 2, 3). General colour pale brown, elytra with only slightly darkened suture, lateral margins and apices; each elytron with a large yellow spot extending from anterior margin up to two thirds of elytral length. Legs and antennae yellowish brown.

Frons concave, uniformly shagreened, minutely, uniformly punctured. Vestiture of whole frontal surface consists of very fine erect and relatively long hairlike setae visible from lateral and dorsal view (not from frontal view). Upper and lateral edges of frons with long hairlike setae; those on upper part until middle of eyes very long and curved towards center of frons. Longest setae convergent in middle of frons, not extending beyond middle of frons; those on lateral edges of flattened lower frontal part become shorter ventrad and are not so curved (Fig. 4); frons is quite different from S. daimio with frontal tufts of hairs attaining epistomal margin (Fig. 5). 


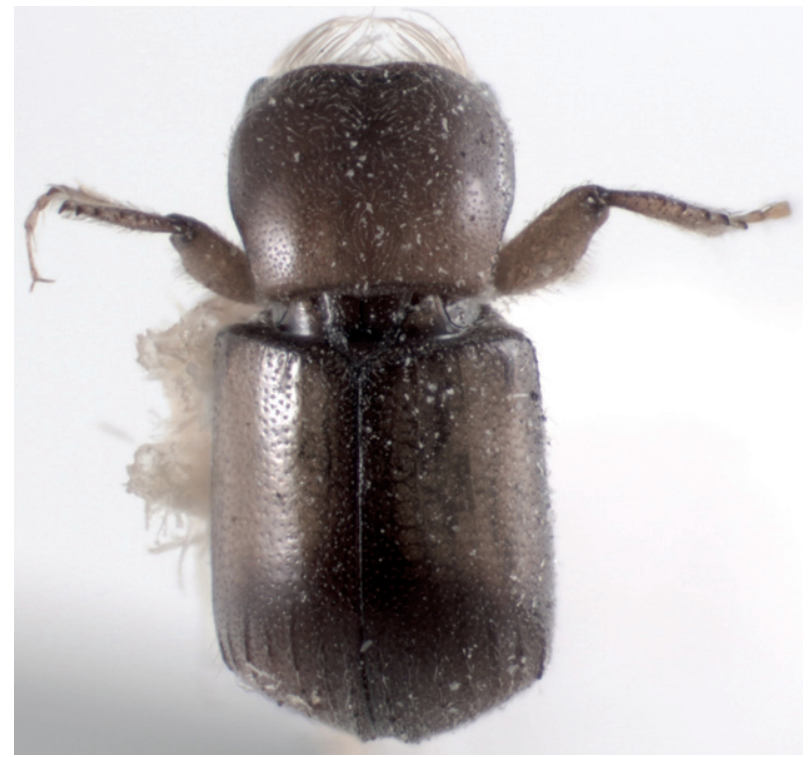

Figure 2. Scolytoplatypus kunala, male, dorsal view.

Pronotum wide and short, 0.8 times as long as wide $(1.9 \mathrm{~mm}$ vs $2.3 \mathrm{~mm})$, widest in anterior third, vestiture of fine and short hair-like setae denser at anterior margin. Pronotal surface shining, minutely punctured, punctures very shallow and set 3-4 diameters apart from each other. Surface between punctures minutely reticulated. Posterior part of pronotum more lightly coloured than anterolateral angles. Lateral margins of pronotum sharply elevated and propleura strongly concave.

Prosternum weakly convex, with an obscure triangular elevation between procoxae, its indistinct pointed apex oriented backwards, and base of triangle forming anterior prosternal margin. This margin is armed with two divergent translucent processes set far apart (Figs 6, 7).

Scutellum small, triangular, flush with elytral surface.

Elytra 1.38 times as long as wide, 2.0 times as long as pronotum, clearly widened posteriorly. Elytral surface minutely punctured, shining, without signs of reticulation. Elytral punctures not organized in rows and interstriae invisible besides at declivity where all interstriae with exception of the first one are finely carinate. First declivital interstriae at declivity are broadly elevated, not carinate and bear 9-10 tubercles of median size, towards elytral apex evidently divergent. Carina on all other interstriae very low and devoid of tubercles. Elytral declivity convex, not impressed. Posterior dark carinate portion of elytra has yellowish and dense recumbent hair-like setae, anterior light portion of elytra is glabrous.

Underside of beetle is uniformly light yellow. Fourth and fifth abdominal sterna with abundant long yellowish hair-like setae protruding beyond abdominal apex.

Front femora without tooth above apex. Front tibiae with three widely set spines at lateral edge and with apical mucro. Tarsi long, third segment not bilobed, fifth segment as long as all previous combined. 


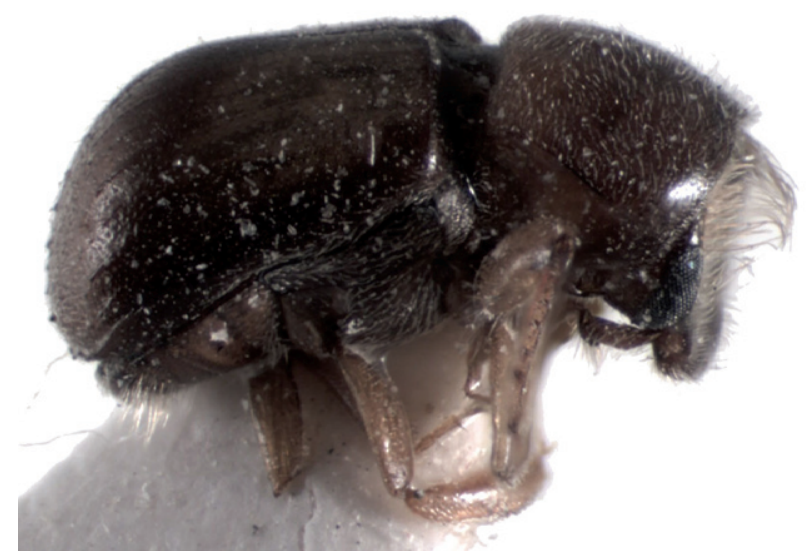

Figure 3. Scolytoplatypus kunala, male, lateral view.

Female. Similar to male, but frons is not impressed and long pubescence at lateral and upper edges of frons is not developed (Fig. 8). Pronotum has a median mycangial pore in its centre.

Length $2.8 \mathrm{~mm}$ (HT $-2.96 \mathrm{~mm}$ ), body stout, 2.15 times as long as wide. Body pale brown, elytral colour pattern essentially as in male, body surface faintly shining.

Head brown, darker compared to other body parts. Frons faintly convex, dull. Frontal surface gently shagreened. Lateral frontal parts near eyes faintly shining. Middle part of frons with a sickle-shaped faintly shining impression above mandibles, upper part of impression near center of the frons with two symmetrically placed small tubercles that are seen with difficulty. Slightly elevated dark median line continues from vertex down to epistomal impression. Frontal surface covered by shallow round punctures. Median part of frons covered by sparse, short erect hair-like setae, with somewhat higher density in middle of frons. Short recumbent hair-like setae are concentrated around eyes. Vertex is covered with round shallow punctures, glabrous. Antennae brown with sand-coloured triangular flat club.

Pronotum subquadrate, surface faintly shining, covered by microscopic round punctures, with faintly developed flattened tubercles laterally from pronotum center. Slightly anteriorly to pronotum middle a well-developed mycangial pore with a bunch of pale fine hair-like setae is developed. Posterior part of pronotum up to the central pore is covered by pale microscopic hair-like setae; anteriorly to the pore, pronotum with more long pale erect hair-like setae. Lateral pronotal margin as in all Scolytoplatypus is acute. Prothorax has an impression for protibiae. Intercoxal piece flat, its lateral margins near apex with bunches of long golden hair-like setae.

Scutellum as in male.

Elytra light brown, faintly shining. Elytral base 1.2 times as wide as pronotum base. Maximal elytral width at beginning of declivity. Declivital margins not evenly rounded toward elytral apex, elytral apex somewhat angular. Dorsum of declivity evenly arched towards apex. Elytra 1.4 times as long as wide. Elytral surface with circular punctures. 

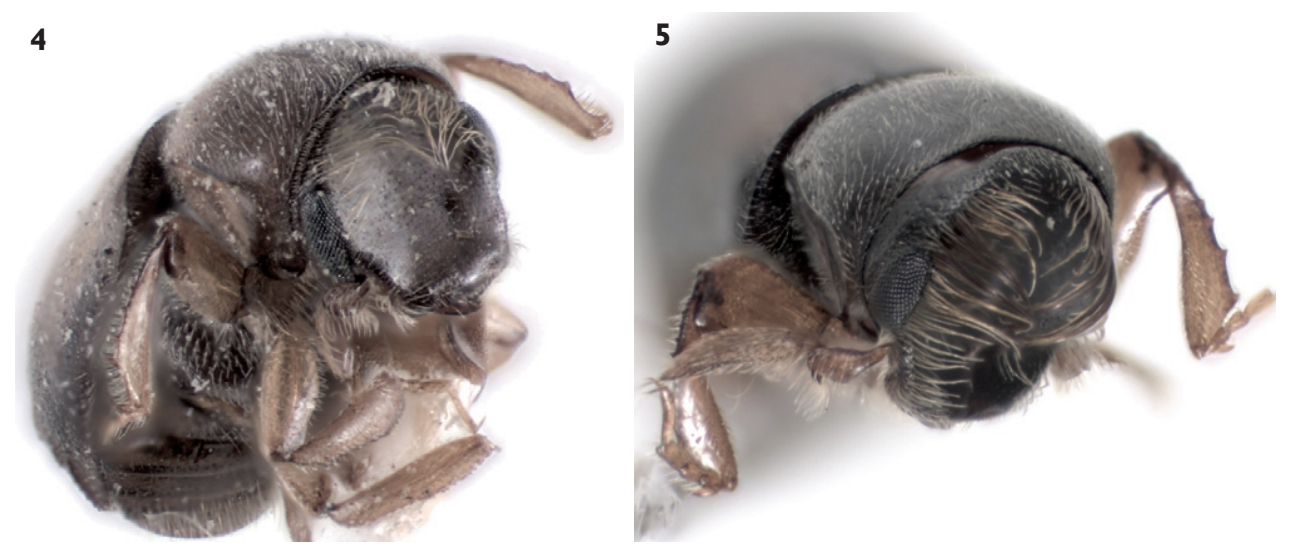

Figure 4, 5. 4 Scolytoplatypus kunala, male, frontal vestiture 5 Scolytoplatypus daimio, male, frontal vestiture.

Strial punctures not deepened and of similar size to interstrial punctures, so that striae are obscure, not clearly seen. Interstriae slightly elevated on declivity, first interstriae with minute tubercles, seen with difficulty. Elytral surface covered with microscopic light hair-like setae.

Metasternum light brown, covered by short pale hair-like setae. Metacoxal cavities with clearly marked raised margin.

Abdomen light brown. Sternites covered by minute shallow round punctures and pale hair-like setae; these setae clearly longer on 3-rd, 4-th and 5-th sternites than on 1 -st and 2-nd sternites.

Legs light yellow. Denticles on outer lateral protibial surface rather strong in the specimen described, but probably intraspecifically variable.

Diagnosis. In habitus the species resembles specimens of $S$. daimio, but smaller in size and has another color pattern on elytra (with only poorly developed light dark pattern). Frontal pubescence essentially as in S. zahradniki Knížek, 2008 or S. tycon Blandford, 1893. Rather short frontal vestiture easily distinguishes the male $S$. kunala from $S$. daimio and $S$. darjeelingi males in which the longest setae extend in a brush from the upper frontal parts up to the epistoma (Fig. 5). Based on the habitus and details of the male prosternum morphology, $S$. kunala is most closely related to $S$. daimio and $S$. darjeelingi, differing from both species in the presence of rather short frontal vestiture in the male. The last feature is present not only in $S$. kunala but also in $S$. tycon, hovewer in the latter, the male prosternum is differently developed and the body is much stouter. The pale area of the elytra is surrounded only by slightly darker zone formed by brown elytral apices and elytral margins, not black as in S. darjeelingi Strohmeyer, 1914. All other Oriental species can be easily distinguished by the features given in the modified key of Beaver and Gebhardt (2006) (see below). In the recently described Scolytoplatypus zahradniki Knížek, 2008 with similar frontal pubescence the male prosternum does possess two processes anteriorly, but they are closely set and not wide apart as in S. kunala. A similar prosternum to $S$. kunala is seen in S. daimio, 


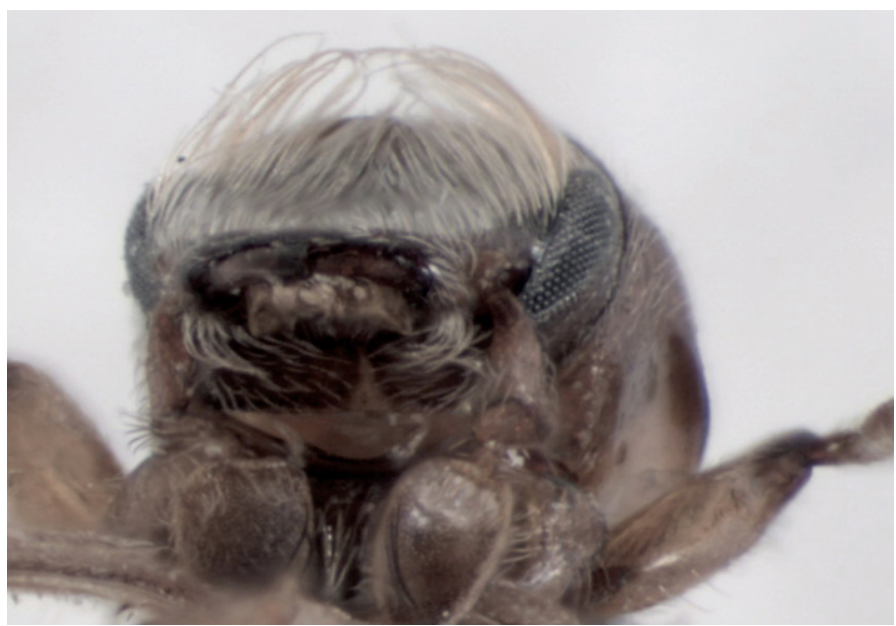

Figure 6. Scolytoplatypus kunala, male, prosternum.

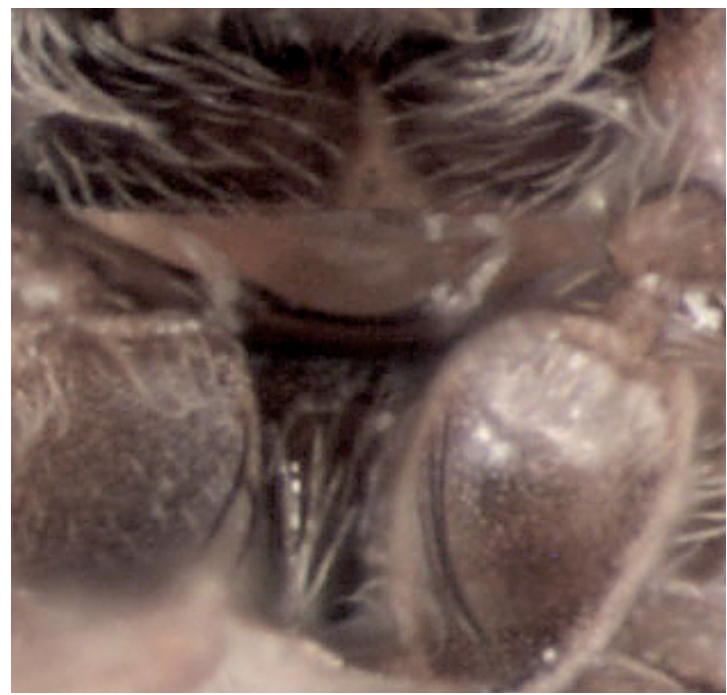

Figure 7. Scolytoplatypus kunala male prosternum organ, enlarged.

but not in S. zahradniki, which possesses closely set translucent processes at anterior margin of pronotum and a distinct type of pronotal elevation with a sharp keel protruding forwards and backwards. The S. zahradniki males can also be distinguished by the clearly carinate elytral interstriae which are only slightly elevated on the S. kunala declivity (Knížek 2008). The female of S. kunala can be distinguished from the females of $S$. daimio and $S$. zahradniki by the smaller body size and by presence of declivital tubercles only on the 1 - st elytral interstria, by very faint striae on the apical part of the elytral declivity.

Unfortunately, the recently published key to Indian Scolytoplatypus by Maiti and Saha (2009) ignores the paper by Beaver and Gebhardt (2006) and uses quite another 


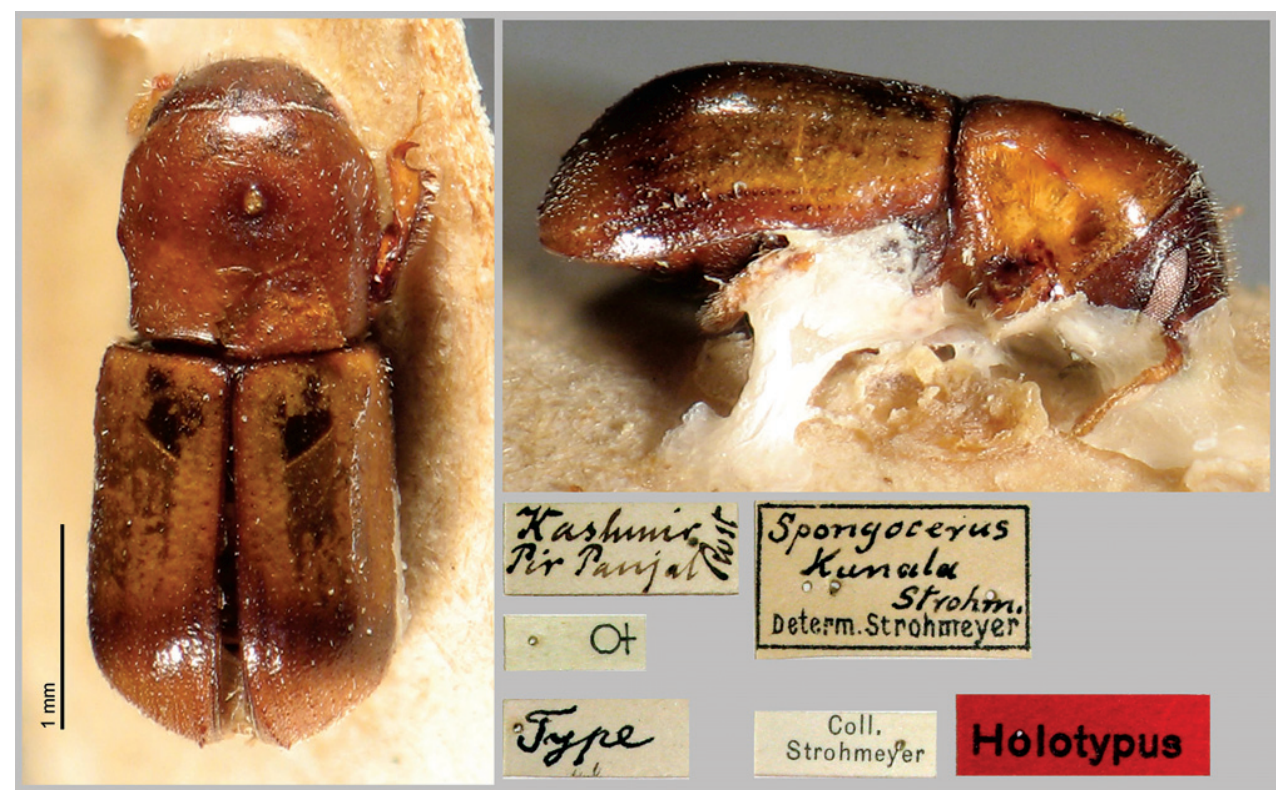

Figure 8. Scolytoplatypus kunala, Holotype, female.

set of features to distinguish species. Importantly, it does not use the male prosternum structure to provide principal features to identify species groups. Three new species were described as new by Maiti and Saha (2008), namely S. gardneri, S. lopchuensis and S. samsinghensis; however use of another set of features to distinguish species does not allow the inclusion of these three species into the key by Beaver and Gebhardt (2006). S. samsinghensis differs from $S$. kunala by the much larger size $(3.75-3.80 \mathrm{~mm}$ versus $2.70-3.00 \mathrm{~mm}$ ), by the uniformly dark reddish brown to blackish brown body color, by the presence of conspicuous interstrial ridges on the elytral disk both in males and in females and also by the very short frontal pubescence both in male and in female. Besides, sparse long, erect declivital hair-like setae present in $S$. samsinghensis male are absent in S. kunala. Both S. lopchuensis and S. gardneri are slightly smaller in size compared to $S$. kunala $(2.55-2.60 \mathrm{~mm}$ vs. $2.70-3.00 \mathrm{~mm})$. The female of $S$. lopchuensis differs from that of $S$. kunala by the absence of the mycetangium pore in the centre of the pronotum, and the female of $S$. gardneri is unknown. Males of both species, $S$. lopchuensis and S. gardneri, are different from $S$. kunala in having even frontal vestiture without a fringe of hair-like setae on the upper frontal rim with their apices converging towards the centre of the frons. S. kunala is very closely related to $S$. darjeelingi Stebbing sensu Maiti and Saha, 2009; however, in contrast to Maiti and Saha's description, S. darjeelingi has very long tufts of hair-like setae originating from the upper part of the frons (Stebbing 1914, Beaver and Gebhardt 2006) and extending to the epistoma near the mandibles.

Discussion. The key to Oriental Scolytoplatypus species males by Beaver and Gebhardt (2006) can be easily modified to include both redescribed S. kunala and recently described S. zahradniki. 
The key to males will be changed from couplet 19

19. Prosternum with a pair of widely separated, translucent, divergent anteriorly processes. Rows of punctures on elytral dorsum not impressed, usually indistinct.

- $\quad$ Prosternum with a pair of closely set translucent processes, with an asymmetrical translucent process, or without translucent processes

19A. Frons with a rather sparse fringe of hair-like setae on each side curving inwardly, convergent to the center of frons but not extending to lower half of frons. $2.7 \mathrm{~mm}$ Scolytoplatypus kunala Strohmeyer

- The incurved brushes of hair-like setae denser and longer, extending beyond middle of frons and usually attaining epistomal margin

22 (species S. shogun, S. daimio and S. darjeelingi)

19B. Prosternum raised in middle in a triangle, the apex anterior or posterior....20

- $\quad$ Prosternum flat or weakly convex, not raised in a triangle. Prosternum without translucent processes at the anterior margin. $3.5-4.5 \mathrm{~mm}$

S. tycon Blandford

20. Apex of prosternal triangle posterior, anterior margin projecting in two rounded lobes, slightly asymmetrical, and with a translucent process on the right side only. 2.8-3.0 mm long ............................... S. ruficauda Eggers

- $\quad$ Apex of prosternal triangle anterior, with two symmetrical, divergent, triangular, closely set translucent processes .21

21. Posterior margin of raised prosternal triangle has a sharp elevation directed posteriorly in the center, apex of prosternal triangle anterior without a pointed tubercle directed downwards. $2.6-3.3 \mathrm{~mm}$.

S. zahradniki Knížek

- Apex of prosternal triangle anterior with a single pointed tubercle directed downwards. 3.1-3.3 $\mathrm{mm}$ long.

S. blandfordi Gebhardt

The key to Oriental Scolytoplatypus species females by Beaver and Gebhardt (2006) can also be modified to include the redescribed species, Scolytoplatypus daimio, and recently described Scolytoplatypus zahradniki Knížek.

The key to females will be changed from couplet 15 .

15. Basal angles of pronotum triangularly produced laterally, acute apically (species S. mikado, S. raja)

- Basal angles of pronotum not strongly produced laterally, approximately rectangular

17. Elytral interstriae carinate in the posterior two thirds of elytra $2.8-3.5 \mathrm{~mm}$...

S. zahradniki Knížek

- Elytral interstria not carinate, with rows of tubercles or striae weakly impressed before declivity or not impressed at all; if carinate than size less than $2.8 \mathrm{~mm}$ 
17A. Elytral striae weakly impressed before declivity; elytral disc with fine hair-like setae on both striae and interstriae. Body length $3.8-4.5 \mathrm{~mm}$

S. tycon Blandford

- $\quad$ Elytral striae not impressed before declivity, or if impressed, then length less than $2 \mathrm{~mm}$

18. Elytral declivity with dense vestiture of long, yellowish hair-like setae 19 (species S. blandfordi, S. darjeelingi, S. pubescens)

- $\quad$ Elytral vestiture of very short hair-like setae or elytra glabrous .21

21. More elongate species, the elytra 1.7-1.9 times as long as pronotum .22 (species $S$. shogun, S. daimio)

- $\quad$ Less elongate species, the elytra at most 1.5 times as long as pronotum.....23

23. Apex of interstriae 2 with a small acutely pointed tooth

24 (species S. carinatus, S. nitidus)

- $\quad$ Apex of interstriae 2 without a tooth................................................. 24A

24A. Larger species, body length $2.8-3.0 \mathrm{~mm}$. Interstriae at the declivity with minute tubercles, clearly seen only at the first interstriae, obscure and seen with difficulty at all other interstriae S. kunala Strohmeyer - $\quad$ Smaller species $1.2-1.8 \mathrm{~mm}$ long

25 (species $S$. nanus, S. minimus, S. pusillus)

\section{Acknowledgments}

Dr. Maxwell Barclay is thanked for the loan of undetermined Dryocoetes specimens from BMNH, from which new species Dryocoetes brownei was described. Dr. Nikolay Nikitsky has kindly allowed authors to work with Indian Dryocoetini and Scolytoplatypodini deposited in the Zoological Museum of Moscow University (ZMMU) and Dr. O.N. Kabakov is thanked for comments on new species trapping locality details. Mr. Lutz Behne (Senckenberg Deutsches Entomologisches Iinstitut, SDEI) is thanked for providing excellent photographs of Strohmeyer's holotype of Scolytoplatypus kunala. Special thanks are due to Dr. Roger Beaver and Dr. Miloš Knížek for helpful comments on the manuscript draft and correcting the language.

\section{References}

Beaver RA, Gebhardt H (2006) A review of the Oriental species of Scolytoplatypus Schaufuss (Coleoptera, Curculionidae, Scolytinae). Mitteilungen aus dem Museum fur Naturkunde Berlin, Deutsche entomologische Zeitschrift 53 (2):155-178.

Knížek M (2008) A new species of Scolytoplatypus (Coleoptera: Scolytidae) from China. Studies and reports of District Museum Prague-East. Taxonomical Series 4 (1-2):119-124.

Maiti PK, Saha N (2009) Fauna of India and the Adjacent Countries : Scolytidae: Coleoptera (Bark-and Ambrosia-Beetles), Vol. I (Part 2). Zoological Survey of India, Kolkata, 246 pp. 
Stebbing EP (1914) Indian forest insects of economic importance. Coleoptera. Eyre and Spottiswoode, London, $648 \mathrm{pp}$.

Strohmeyer H (1908) Beschreibung zweiter neuer Borkenkäfer (Ipidae) aus dem westlichen Himalaja und des Scolytoplatypus raja Blandford. Entomologische Wochenblatt (Insecten - Börse). 25 (39): 161.

Wood SL, Bright DE (1992) A catalog of Scolytidae and Platypodidae (Coleoptera). Part 2: Taxonomic index. Great Basin Naturalist Memoirs 13(A): 1-833; 13(B): 835-1553. 